\title{
Designing GDPR Data Protection Principles in Systems Development
}

\author{
Fredrik Blix, Salah Addin Elshekeil, Saran Laoyookhong \\ Department of Computer and Systems Sciences Stockholm University Stockholm, Sweden
}

\begin{abstract}
Data protection by design is a principle to systems development meaning that the protection of personal data is built into the systems design from the start. For many jurisdictions, this principle is becoming a legal requirement. Using a research approach based on design science, a framework is constructed helping systems developers achieve data protection by design in a systematic manner. The framework articulates how the business requirements can be captured, assessed, and implemented in the systems development. Examples of how the data protection principles can be concretely implemented is also presented.
\end{abstract}

\section{Introduction}

The European General Data Protection Directive GDPR is the new European-wide regulation aimed at all businesses and other legal entities that are processing personal data (information that is relating to an identified or identifiable living person). In practice, GDPR means that businesses will have to do a lot of work to secure the processing of such data. The difference between general cybersecurity efforts and these efforts are that GDPRs focus is not on cybersecurity risks in general - it is concerned with the protection of basic human rights (such as the right not to be discriminated against because of ethnicity, sex, etc.). One of the requirements of GDPR is that all systems - both old legacy systems and new systems that are developed now, if they handle personal data - need to be designed with data protection in mind. This principle is called data protection by design. The problem is that most businesses have not been required to consider privacy nor data protection by design when they developed their systems, since this has not been a legal requirement before. As more and more jurisdictions require this, the problem is growing. Even though there are no systematic surveys, one can estimate that probably less than 2 systems out of 10 would be considered designed with privacy in mind if analyzed. The problem is owned by businesses owning (or renting) systems processing personal data. The practical relevance of this study is take one step towards the helping businesses solve how they can achieve data protection by design in a costeffective manner. The theoretical relevance is filling a void in studies on data protection by explicitly tackling privacy by design - not in principle only, but how it relates directly to systems development.
This paper presents the study and its results. In section 2, presents a systematic literature review in summary. In section 3 the overall research approach and - method is covered. Section 4, presents the resulting framework and finally section 5 contains concluding remarks.

\section{Literature review}

The authors aimed to answer the following questions through the literature review:

- What are the existing privacy and data protection by design principles?

- How can privacy and data protection by design principles be implemented in IT Systems?

- Are there any existing case studies concerned with the implementation of privacy or data protection by design?

- Are there any established standards for implementing privacy or data protection by design?

The systematic literature review followed was based on Rondolph's guidelines [1] on how to conduct a thorough literature review. The sources of the data collection were academic and popular articles identified through online digital libraries for research publications as well as through web search engines. The data was then evaluated, analyzed to find patterns, and the answers to the questions posed.

\subsection{Definition of privacy by design}

Privacy has been a controversial topic for long time; there were many attempts to define what privacy is according to the context and the environment [2]. Warren and brandies defined privacy term and the "right to be left alone" back in 1890 [3]. After that, there were number of definitions of privacy. On the legal side, privacy was perceived and defined differently from country to country, especially in the EU where privacy was lawfully granted for EU Citizens in the European commission of human rights. Privacy by design was introduced in the 90's by Ann Cavoukian who defined the concept as "Refers to the philosophy and approach of embedding privacy into design specification of various technologies" [4]. The seven principles were introduced and became the foundation of Privacy by Design concept for many research. Furthermore, P. Schaar [5] introduced six different objectives to consider when designing 
processing systems, and argued that these principles should be bonded for technology designers, and producers. Also, the 11 privacy principles were in introduced according to the standard ISO/IEC 29100 [6].

\subsection{Privacy by design and data protection principles}

There is no consensus about privacy by design principles, authors and regulations introduced different principles. Ann Cayoukian [4] who defined privacy by design introduced seven principles, these principles are generic and not easily can be translated into IT requirements. While Schaar [5] has 6 principles, which are missing important principle such as accountability. Standards such as ISO 29100 introduced 11 principles, that are detailed and overlapped with GDPR and other privacy principles. Purpose limitation for example is newly introduced in GDPR, while data quality principle was introduced by Schaar [5], but ISO 29100 called it accuracy and quality. Accountability principle was introduced in ISO29100 and GDPR. Consent is also another principle was introduced by ISO29100, but no one else introduced this principle. In GDPR it is considered part of the lawfulness, fairness and transparency. GDPR [7] the new EU data protection regulations has introduced seven data protection principles Table 1, which will be the focus on this research. These principles have to be implemented in the systems that process personal data by design and by default according to GRPR article 25. All establishments who are processing EU Citizens personal data inside and outside EU will be subject for compliance. The notation (DPP 1-7) is used to refer to these principles in this paper.

Table 1. Data Protection Principles

\begin{tabular}{|l|l|l|}
\hline$\#$ & Notation & Data Protection Principle \\
\hline $\mathbf{1 .}$ & DPP1 & $\begin{array}{l}\text { Lawfulness, fairness and } \\
\text { transparency }\end{array}$ \\
\hline $\mathbf{2 .}$ & DPP2 & Purpose Limitation \\
\hline $\mathbf{3 .}$ & DPP3 & Data Minimization \\
\hline $\mathbf{4 .}$ & DPP4 & Storage Limitation \\
\hline $\mathbf{5 .}$ & DPP5 & Integrity and Confidentiality \\
\hline $\mathbf{6 .}$ & DPP6 & Accuracy \\
\hline $\mathbf{7 .}$ & DPP7 & Accountability \\
\hline
\end{tabular}

\subsection{Approaches of privacy by design implementation}

Privacy implementation approaches can be divided into two, management and process approach and engineering and technology approach. In Figure
1, previous researches grouped based on patterns and approaches.

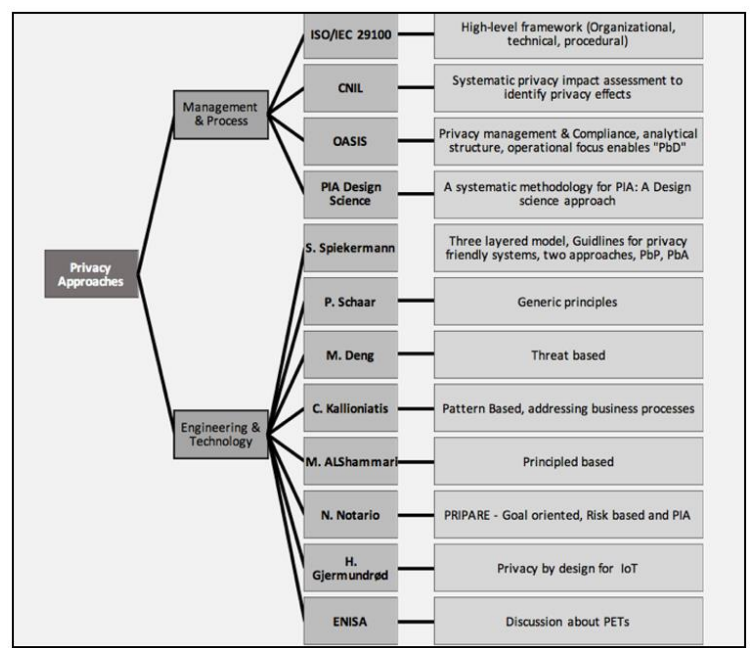

Figure 1. Privacy by design implementation approaches

2.3.1. Approaches of privacy impact assessment and related approaches. Wright defined that Privacy Impact Assessment (PIA) is "a form of risk assessment, an integral part of risk management" [8], while Wadhwa [9] viewed the PIA as a privacy management tool. These definitions can be implied that the PIA can manage the risk concerning the privacy and include a similar process to the risk management. Moreover, CNIL defined a privacy risk given the processing of personal data that has impacts on the privacy of data subjects and also stated that another aspect of the PIA is to determine suitable measures that complied with the legal requirements [10]. The development of PIA went back since 1996 when the US Internal Revenue Service issued its IRS PIA, endorsed by the Federal Chief Information Officers Council [10]. Throughout the years, public sectors concerning information and privacy commissioner from various countries like Hong Kong, Canada, New Zealand and Austria has released their version of PIA to suit each need. Then, in December 2007, the Information Commissioner's Office (ICO)'s PIA Handbook was released and is considered the first PIA Handbook in Europe. After that, in 2008, the International Organization for Standardization (ISO) published the PIA 22307:2008 standard. In the following year, the European Commission (EC) issued a recommendation on the implementation of privacy and data protection principles for RFID application which was endorsed by Article 29 [11] and later became EC's PIA framework for RFID in February 2011. Also, there are similar tools such as Data Protection Impact Assessment (DPIA) which was introduced by the 
European Commission as an evaluation and decision-making tool.

2.3.2. Challenges of privacy by design. Privacy by design is a new topic, with divergent views on both the principles and the approaches. There is no comprehensive framework that covers all aspects of privacy and risk-based approach. The lack of framework might be attributed to the controversial topic of privacy and no consensus on the privacy principles. As a result, there are different views on how privacy can be realised in organizations in general and in IT systems. At the same time, few case studies represent privacy implementation in IT systems. In conclusion, no established comprehensive risk-based standards or framework covers legal, technical and organisational requirements.

\section{Method}

Since there is no comprehensive framework for translating GDPR into system requirements, the focus is on develop a new framework and evaluate it through application. This research work follows a design science methodology to build the artefact (here, the framework) and use a case study to evaluate and improve the artefact. Both interviews and literature review were used in parallel to explicate problem and define the requirements of the artefact. There was a total of five interviews conducted with both management teams from an IT security company and members from start-up company who is developing a system that processes the sensitive personal data based on artificial intelligence. In the first interview, together with the management team, the researchers concluded that the lack of knowledge to interpret the GDPR into clear technical requirements was the most pressing problem. The CEO of the start-up company attended the second interview, resulting in that all respondents agreed on the need to development a versatile and flexible framework with the goal to guide businesses to identify the needed organisational and technical information- and cybersecurity measures, resulting in privacy by design, for an IT system. The researchers used creative methods to collect and select ideas using perspectives as 'how the framework should be built' and 'how the developed framework will be used in the research work'. The researchers developed the framework by identifying GDPR requirements, data protection risks and cybersecurity measures (security controls), map them with data protection principles, and finally by identifying existing approaches and security requirements as well as identifying other important factors. The rest of the interviews were conducted while applying the developed framework through the case study, to form a basis for the evaluation. The researchers analyzed the system of the start-up company and their business context to select an initial set of appropriate security measures, then assessed the system to define the data protection requirements. Upon applying the framework to the case study, the researchers learned about the necessity to improve the framework and synthesised the new findings to create an improved and refined version of the suggested framework (as presented in conclusions).

\section{Results}

\subsection{Construction of a framework}

The data protection principles (DPP1-7 in Table 1), identified through the literature review, forms the basis for the results since these principles represent what is to be achieved by any privacy efforts. In addition, these principles are referred to from the European GDPR regulation, and thus forms part of legal requirements in many jurisdictions. The literature review also revealed other approaches to privacy, privacy impact assessment and privacy risk identification that proved useful. Even though the set of potential privacy measures (organizational and technical) that can be applied is almost unlimited, a limited number of such measures - the most commonly used - were listed and subsequently mapped back to the seven data protection principles. The mapping answers the question, "What privacy measures can help satisfy which the data protection principle DPPX?".

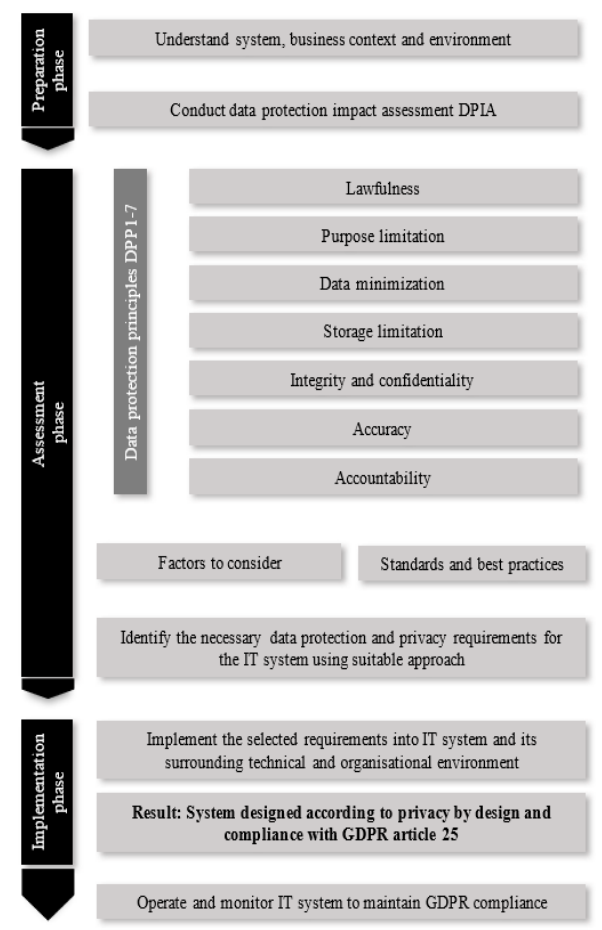

Figure 2. Framework for Privacy by Design, APSIDAL 
Which privacy measures are suitable in each situation depends on many other internal (systemsrelated) and external (outside of the system) factors. GDPR mentions seven factors which were supplemented with four factors from other sources. In total, this forms the basis for the suggested framework presented here (see Figure 2). This framework is the improved and refined version after the evaluation (see method chapter for evaluation details).

\subsection{Factors to consider when applying the framework}

The severity of the impact on the data subject and the understanding of the system from the previous phase determine how comprehensive the measures shall be implemented. Also, there are aspects to consider when choosing the measures. Provision 25 of the GDPR stated that the controller/processor should consider several factors when designing data protection in the systems or products. Those seven factors are state of the art technology, cost, nature, scope, context, purposes of processing, and the risks associated with the processing. In this research, both researchers synthesised these seven factors with the following additional factors to create a basis to find common ground among business, technical and data subjects' requirements.

1) Complexity - The implementation and operation of these measures should not be too complex that the data controllers and data subjects have a difficulty using it.

2) Usability - The measures with higher usability are more likely to have data controllers efficiently operate it.

3) Efficiency - Even with the same objective, different measures might generate different results. The efficiency determines how smooth the measures are operating.

4) Effectiveness - The effectiveness of the control determines how through the control achieve its purpose. The effective control shall fulfil its objective extensively compare to the weak one. Altogether, these 11 factors will be considering in the framework to guide the selection of the measures.

\subsection{Standards and best practices}

Table 2 presents standards and best practices that the users of this framework can refer to find a complete list of controls tailored to their environment.

\subsection{Data Protection and Privacy Requirements Elicitations for IT Systems}

In this process of the assessment phase, the goal is to elicit and identify the data protection and privacy requirements of the IT systems. To make this framework applicable for any IT systems under developments and operating IT systems, the researchers propose two approaches. The first approach is to use tools such as threat modelling or LINDDUN [12] during the design phase of the IT system. In case the IT system is already in operation, the second approach is to use static code review, effective code review, or penetration testing to identify the vulnerabilities that can be fixed by applying add-on measures. Table 3 explains the different approaches for data protection and privacy requirements elicitations.

\subsection{Data Protection Principles Mapped to Data Lifecycle}

During the application of the framework on ChatBot, the researchers realised the importance of mapping the data protection principles into the data life cycle phases of an IT system. This mapping will help the practitioner of this framework to have a clear understanding of the data protection principles and will aid in the selection of the adequate technical and organisational measures for each phase. The data life cycle starts with data collection phase, where data minimization principle should be considered. The data controllers should collect only the necessary personal data that the processing cannot be performed without. In the data processing phase, purpose limitation is relevant, whereby the data controllers should process these collected data for the purposes they were collected for. Data storage is the third phase, where personal data should not be stored longer that it is required. Moreover, accuracy, integrity and confidentiality and accountability principles apply to all data lifecycle phases and the corresponding principles. Finally, it is essential for the data controllers to base all activities on the lawfulness, fairness and transparency principle. Figure 3 visualises the mapping between data life cycle in IT systems and seven data protection principles.

\section{Conclusion}

By applying the suggested APSIDAL framework, businesses and other organizations can take an important step towards complying with the principle of data protection be design and by default as required in an increasing number of jurisdictions. 
Table 2. Sources for Data Protection, Privacy and Security Measures

\begin{tabular}{|c|c|c|}
\hline Domain & $\begin{array}{l}\text { Standards } \\
\text { and Best } \\
\text { Practices }\end{array}$ & Description \\
\hline \multirow[t]{5}{*}{ Organizational } & ISO 27000 & $\begin{array}{l}\text { Set of standards that help organisations to secure their information } \\
\text { assets }\end{array}$ \\
\hline & ISO 29100 & $\begin{array}{l}\text { Framework and set of controls for organisations who process } \\
\text { personally identifiable information }\end{array}$ \\
\hline & ISO 27018 & $\begin{array}{l}\text { Set of controls that meant to protect personally identifiable } \\
\text { information in public cloud }\end{array}$ \\
\hline & UCF & $\begin{array}{l}\text { A unified compliance framework is a library that maintains a } \\
\text { comprehensive set of controls applicable to both organizational and } \\
\text { technical needs }\end{array}$ \\
\hline & COBIT 5 & $\begin{array}{l}\text { A business framework produced by ISACA which includes various } \\
\text { enablers for Securing Sensitive Personal Data or Information (SPDI) } \\
{[12]}\end{array}$ \\
\hline \multirow[t]{2}{*}{ Technical } & NIST $800-53$ & Technical Security controls for information systems \\
\hline & ENISA & $\begin{array}{l}\text { The Privacy enhancing technologies Guide, "Privacy and Data } \\
\text { Protection by Design from policy to engineering } 2015 \text { ", contains a set } \\
\text { of technical privacy measures to build privacy into systems and } \\
\text { services }\end{array}$ \\
\hline
\end{tabular}

Table 3. Approaches for Data Protection, Privacy, and Security Requirements Elicitation

\begin{tabular}{|c|c|c|}
\hline Approach & Technique/Method & Description \\
\hline \multirow[t]{4}{*}{$\begin{array}{l}\text { System } \\
\text { Under } \\
\text { Design }\end{array}$} & LINDDUN & $\begin{array}{l}\text { LINDDUN is a comprehensive framework for identifying privacy } \\
\text { threats in software based systems. It used methods such as data flow } \\
\text { diagrams and STRIDE to analyse the systems and identify privacy } \\
\text { threats. Also, it contains a mapping for each privacy threat and the } \\
\text { existing countermeasures to mitigate it [12] }\end{array}$ \\
\hline & Threat Modelling & $\begin{array}{l}\text { Threat Modelling is often used in the design phase of the systems } \\
\text { where threats can be identified. Threat modelling can also use } \\
\text { different techniques such as STRIDE, DREAD, misuse cases attack } \\
\text { trees, and ASF to identify and analyse the potential threats [13] }\end{array}$ \\
\hline & $\begin{array}{l}\text { Common } \quad \text { Criteria } \\
\text { (ISO/IEC 15408) }\end{array}$ & $\begin{array}{l}\text { Common Criteria is an international standard for security } \\
\text { requirements in information systems. It has re-used repository of } \\
\text { security requirements. These requirements allow both the developers }\end{array}$ \\
\hline & & $\begin{array}{l}\text { and the end-users to evaluate and gain trust on the products according } \\
\text { to the implemented security functions [13] }\end{array}$ \\
\hline \multirow[t]{2}{*}{$\begin{array}{l}\text { Operational } \\
\text { System }\end{array}$} & $\begin{array}{l}\text { Penetration and } \\
\text { Vulnerability testing }\end{array}$ & $\begin{array}{l}\text { When the system is in operations phase, penetration testing and } \\
\text { vulnerability scanning can be used to identify system deficiencies } \\
\text { from the attacker points of view. Therefore, system developers can fix } \\
\text { the identified vulnerabilities which enhanced the security. Penetration } \\
\text { testing is a too little too late method and should not be the only way to } \\
\text { assess the security and identify security requirements [14] }\end{array}$ \\
\hline & $\begin{array}{l}\text { Static and Dynamic } \\
\text { Code Reviews }\end{array}$ & $\begin{array}{l}\text { Static and dynamic code reviews is another way of reviewing the } \\
\text { software. Static code reviews can be conducted by a specialised } \\
\text { security expert or tools to identify vulnerabilities in the code. } \\
\text { However, not all vulnerabilities can be identified using this method } \\
\text { [13]. }\end{array}$ \\
\hline
\end{tabular}




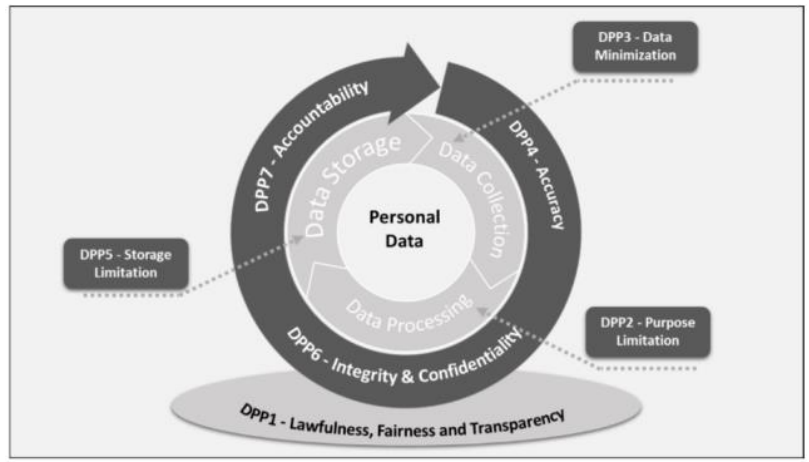

Figure 3. Date Protection Principles Mapped to Data Lifecycle

The framework shows step-by-step activities that needs to be carried out, tied to the three main identified phases (preparation, assessment and implementation phase). Other factors, standards and tools can be used in each of the identified phases of the framework to achieve the desired outcomes. For those needing more specific guidance, Appendix 1 shows the identified organizational and technical data protection and security measures found potentially valuable, tied to each of the seven data protection principles.

\section{References}

[1] J. Randolph, "A Guide to Writing the Dissertation Literature Review," Practical Assessment, Research \& Evaluation, vol. 14, no. 13, pp. 1-13, 2009.

[2] C. T. Di Iorio and F. Carinci, Privacy and Health Care Information Systems: Where Is the Balance? Berlin: Springer, 2013, pp. 77-105.

[3] S. D. Warren and L. D. Brandeis, "The Right to Privacy," Harvard Law Review., vol. IV, no. 5, p. 193220, 15 Dec 1890.

[4] A. Cavoukian, "Privacy by Design - Information and Privacy Commissioner," 2007. [Online]. Available: https://www.ipc.on.ca/wp-

content/uploads/Resources/7foundationalprinciples.pdf. [Accessed 229 2017].

[5] P. Schaar, "Privacy by Design," Identity in the Information Society, vol. 3, no. 2, p. 267-274, August 2010.

[6] International Standard ISO/IEC 29100, "Privacy framework Technologies 29100," ISO/IEC, 2011.

[7] Official Journal of the European Union, "General Data Protection Regulation - GDPR," Official Journal of the European Union, vol. 2016/679, p. 119/1, 2742016.

[8] D. Wright, R. Gellert, S. Gutwirth and M. Friedewald, "Minimizing technology risks with PIAs, precaution, and participation," IEEE Technology and Society Magazine, vol. 30, no. 4, pp. 47-54, 2011.

[9] K. Wadhwa and R. Rodrigues, "Evaluating privacy impact assessments," Innovation: The European Journal of Social Science Research, vol. 26, pp. 161-180, 2013.

[10] Commission Nationale de l'Informatique et des Libertés, "PRIVACY IMPACT ASSESSMENT (PIA)," 6 2015. [Online]. Available:https://www.cnil.fr/sites/ default/files/typo/document/CNIL-PIA-1Methodology.pdf. [Accessed 229 2017].

[11] European Commission, "Privacy and Data Protection Impact Assessment Framework for RFID Applications," no. January, pp. 1-24, 2011.

[12] A. W. Kadam and S. Vutha, "Securing Sensitive Personal Data or Information," ISACA, 2012.

[13] M. Deng, K. Wuyts, R. Scandariato, B. Preneel and W. Joosen, "A privacy threat analysis framework: supporting the elicitation and fulfillment of privacy requirements," Requirements Engineering, vol. 16, pp. 332, 2011.

[14] D. Mellado, E. Fernández-Medina and M. Piattini, "A common criteria-based security requirements engineering process for the development of secure information systems," Computer Standards \& Interfaces, no. 29, pp. 244-253, 2007.

[15] B. Arkin, S. Stender and G. Mcgraw, "Software Penetration Testing," The IEEE Computer Scociety, 2005.

[16] OWASP, "Static Code Analysis," [Online]. Available: https://www.owasp.org/index.php/Static_Code_Analysis. [Accessed 1002 2018].

[17] OWASP, "Application Threat Modeling," 2015. [Online]. Available:https://www.owasp.org/index.php/ Application_Threat_Modeling. [Accessed 1002 2018]. 
Appendix I. Identified Organizational and Technical Data Protection and Security Measures

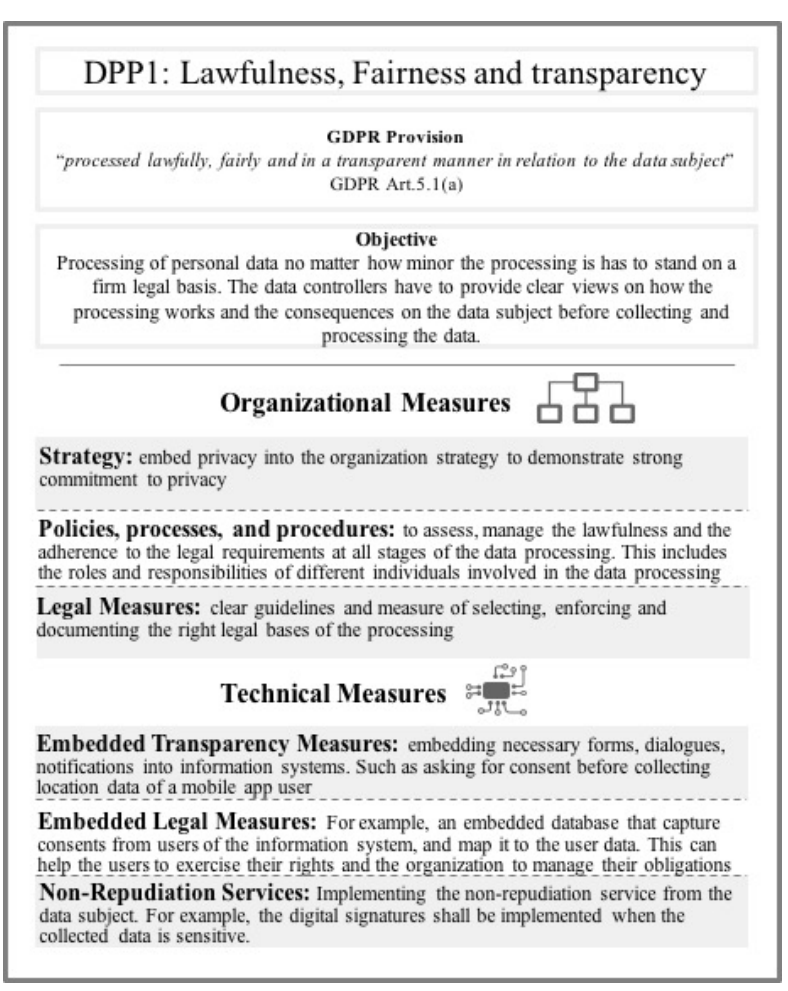

\begin{tabular}{|c|}
\hline DPP2: Purpose Limitation \\
\hline $\begin{array}{l}\text { GDPR Provision } \\
\text { "collected for specified, explicit and legitimate purposes and not further processed in a } \\
\text { manner that is incompatible with those purposes; further processing for archiving } \\
\text { purposes in the public interest, scientific or historical research purposes or statistical } \\
\text { purposes shall, in accordance with Article } 89(1) \text {, not be considered to be incompatible } \\
\text { with the initial purposes" GDPR Art. } 5.1(\mathrm{~b})\end{array}$ \\
\hline $\begin{array}{l}\text { Objective } \\
\text { Purpose limitation requires the data controllers to define the reasons for data collection } \\
\text { and processing. Both data controllers need to ensure that the data is processed } \\
\text { according to the original purpose. The data should not be processed when the } \\
\text { purpose has changed without firm legal ground. Also, data traceability throughout the } \\
\text { data lifecycle is needed to know when the data processing is not according to the } \\
\text { original purpose anymore. }\end{array}$ \\
\hline 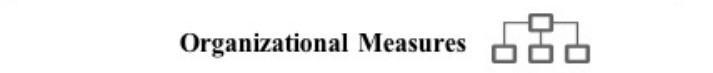 \\
\hline $\begin{array}{l}\text { Strategy: Privacy strategy aligned with organization strategy, and in some cases } \\
\text { changing to the business model to uphold the purpose limitation }\end{array}$ \\
\hline $\begin{array}{l}\text { Policies, processes, and procedures: to assure the personal data is used to the } \\
\text { purpose it was collected for. The processing must be according to the purpose during } \\
\text { the data processing lifecycle. Any deviation must be captured, and dealt with. }\end{array}$ \\
\hline Technical Measures \\
\hline $\begin{array}{l}\text { Data Inventory: functionality to trace back the purpose of the data collection, this } \\
\text { can be achieved by adding meta-data or tagging to the personal data, this can be linked } \\
\text { to the data minimization and storage limitation purposes }\end{array}$ \\
\hline $\begin{array}{l}\text { Reporting: automatic notification and reporting functionality embedded } \\
\text { into the information systems }\end{array}$ \\
\hline
\end{tabular}

\begin{tabular}{|c|}
\hline DPP3: Data Minimization \\
\hline $\begin{array}{l}\text { GDPR Provision } \\
\text { "adequate, relevant and limited to what is necessary in relation to the purposes for which } \\
\text { they are processed" GDPR Art. } 5.1(\mathrm{c})\end{array}$ \\
\hline $\begin{array}{l}\text { Objective } \\
\text { Data minimization involves reducing the amount of the collected data to what is } \\
\text { necessary that the interaction with the data subject is satisfied without. }\end{array}$ \\
\hline 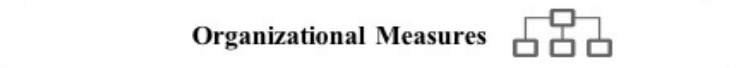 \\
\hline $\begin{array}{l}\text { Strategy: embed privacy into the organization strategy to demonstrate strong } \\
\text { commitment to privacy }\end{array}$ \\
\hline $\begin{array}{l}\text { Policies, processes, and procedures: to assess, manage the lawfulness and the } \\
\text { adherence to the legal requirements at all stages of the data processing. This includes } \\
\text { the roles and responsibilities of different individuals involved in the data processing }\end{array}$ \\
\hline $\begin{array}{l}\text { Identity \& Access Management: clear guidelines and measure of selecting, } \\
\text { enforcing and documenting the right legal bases of the processing }\end{array}$ \\
\hline Technical Measures \\
\hline $\begin{array}{l}\text { Centralized Storage: limiting the distribution of storing personal data in } \\
\text { distributed environment, and consolidate the personal data in central storage can } \\
\text { contribute to data minimization }\end{array}$ \\
\hline $\begin{array}{l}\text { Data Pseudonymization: Encrypting some of the data fields that can link the } \\
\text { data to persons such as names, birthdays, address. Keys should be handled carefully } \\
\text { to prevent recovering the encrypted fields. }\end{array}$ \\
\hline $\begin{array}{l}\text { Strip Unused meta data: files, documents, videos can contain personal data } \\
\text { about the author, the geographical location of the user and IP addresses that may not be } \\
\text { necessary for the data processing. Cleaning these meta-data might be necessary }\end{array}$ \\
\hline $\begin{array}{l}\text { Intermediary Proxies: Data Collection and data transmission through } \\
\text { intermediary proxies to filter and anonymize personal data such as IP addresses, and } \\
\text { cookies }\end{array}$ \\
\hline
\end{tabular}

\begin{tabular}{|c|}
\hline DPP4: Accuracy \\
\hline $\begin{array}{l}\text { GDPR Provision } \\
\text { "adequate, relevant and limited to what is necessary in relation to the purposes for which } \\
\text { they are processed" GDPR Art. } 5.1 \text { (c) }\end{array}$ \\
\hline $\begin{array}{l}\text { Objective } \\
\text { To take necessary steps to ensure the accuracy of data obtained and to verify the data } \\
\text { source. Furthermore, any challenges to the accuracy of information shall be } \\
\text { considered and keep up to data when necessary. In the information technology } \\
\text { system, the accuracy of a digital record can also be measured by the ability of anyone } \\
\text { to understand what the record says correctly. }\end{array}$ \\
\hline Organizational Measures $\square$ 무 \\
\hline $\begin{array}{l}\text { Data Completeness Awareness: raise the awareness among employees and } \\
\text { anyone responsible for data collection and processing about the importance of } \\
\text { collecting complete and accurate personal data, therefore, preventing wrong decisions }\end{array}$ \\
\hline $\begin{array}{l}\text { Data Management: roles, responsibilities, and procedures to insure data quality } \\
\text { across the organization. Controls on data collection, and processes to allow data } \\
\text { subjects keeps their data accurate and always up to date }\end{array}$ \\
\hline $\begin{array}{l}\text { Data Normalization: Guidelines and procedures to on the accepted data formats } \\
\text { such as date, address, name, and language formats. }\end{array}$ \\
\hline Technical Measures = \\
\hline $\begin{array}{l}\text { Input Validation: Validate all inputs to information systems, and allow } \\
\text { only valid data and formats to the system. For example allow only UK } \\
\text { date format. }\end{array}$ \\
\hline $\begin{array}{l}\text { Data Dispute Handling: functionalities to notify data subjects about any changes } \\
\text { to personal data in the information systems, and measures to allow data subjects } \\
\text { object or report any issues about their personal data processed in the systems }\end{array}$ \\
\hline $\begin{array}{l}\text { Data Cleansing: functionalities to analyze the correctness, completeness and } \\
\text { consistency of personal data in information systems, and delete inaccurate or } \\
\text { incomplete data. }\end{array}$ \\
\hline
\end{tabular}




\section{DPP5: Storage Limitation}

GDPR Provision

kept in a form which permits identification of data subjects for no longer than is necessary for the purposes for which the personal data are processed; personal dat may be stored for longer periods insofar as the personal data will be processed solety for archiving purposes in the public interest, scientific or historical research purposes or statistical purposes in accordance with Article $89(I)$ subject to implementation of the appropriate technical and organizational measures required by this Regulation in order to safeguard the rights and freedoms of the data subject" GDPR Art. 5.1(e)

Objective

Storage limitation principle focuses on keeping the identifiable data for only the period that the data serve its purpose. The data controllers have full responsibility to maintain track of the data and remove it when it is no longer being processed for its original purpose.

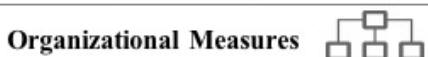

Awareness: awareness can be vital to limit the storage of personal data. Employees tend to keep as much as date if they needed it in the future.

Data Lifespan: clear policies, and guidelines on the lifespan of every data sets. This needs to be defined with the business functions within the organization to avoid deleting
necessary data that can be important for to conduct business or other obligations.

\section{Technical Measures}

Tractability: functionality in the information system that can report and visualize the route the actual data data to the backup, and or other distributed copies. This can the route the actual data data to the backup, and
enable organization to remove unnecessary data

Self-wiping: For example, an embedded database that capture consents from users of the information system, and map it to the user data. This can help the users to exercise their rights and the organization to manage their obligations

Reporting: Implementing the non-repudiation service from the data subject. For example, the digital signatures shall be implemented when the collected data is sensitive.

\begin{tabular}{|c|}
\hline DPP6: Confidentiality and Integrity \\
\hline $\begin{array}{l}\text { GDPR Provision } \\
\text { "processed in a manner that ensures appropriate security of the personal data, } \\
\text { including protection against unauthorized or unlawful processing and against } \\
\text { accidental loss, destruction or damage, using appropriate technical or } \\
\text { organizational measures" GDPR Art. 5.1(f) }\end{array}$ \\
\hline $\begin{array}{l}\text { Objective } \\
\text { Integrity and confidentiality are part of the foundation of information security. } \\
\text { Protecting the privacy of the data subject by maintaining its integrity is to maintain the } \\
\text { accuracy and consistency of stored data. Also, the confidentiality of the data is } \\
\text { maintained by protecting the information from disclosure to unauthorised access. The } \\
\text { measures for this principle shall be implemented and operated throughout the data } \\
\text { lifecycle. }\end{array}$ \\
\hline 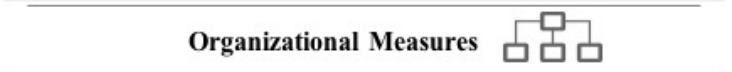 \\
\hline $\begin{array}{l}\text { Identity \& Access Management: embed privacy into the organization strategy } \\
\text { to demonstrate strong commitment to privacy }\end{array}$ \\
\hline $\begin{array}{l}\text { Encryption \& Key Management: to assess, manage the lawfulness and the } \\
\text { adherence to the legal requirements at all stages of the data processing. This includes } \\
\text { the roles and responsibilities of different individuals involved in the data processing }\end{array}$ \\
\hline $\begin{array}{l}\text { Physical security and data processing locations: clear guidelines and } \\
\text { measure of selecting, enforcing and documenting the right legal bases of the processing }\end{array}$ \\
\hline Technical Measures \\
\hline $\begin{array}{l}\text { End to end encryption: encrypting personal data at rest, in transit, and in use } \\
\text { when possible. Depending on the sensitivity of personal data Other techniques such as } \\
\text { anonymization and psudonymization can achieve the same objective }\end{array}$ \\
\hline $\begin{array}{l}\text { Data Validation: preserving the integrity of the data in transit and at rest by using } \\
\text { hashes and input validation when capturing and storing personal data }\end{array}$ \\
\hline $\begin{array}{l}\text { Authentication: adequate level of authentication depending on the level of risk } \\
\text { based on (something you are something you have or something you know) principle. } \\
\text { Combination of two can be necessary for sensitive personal data processing }\end{array}$ \\
\hline $\begin{array}{l}\text { Authorization: access rights management, by using models such as role based or any } \\
\text { other models to insure data always kept secret, and prevent the risk of disclosure of } \\
\text { personal data to unauthorized individuals. }\end{array}$ \\
\hline
\end{tabular}

\section{DPP7: Accountability}

GDPR Provision
"kept in a form which permits identification of data subjects for no longer than is necessary for the purposes for which the personal data are processed; personal dat

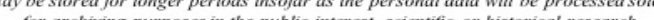
for archiving purposes in the public interest, scientific or historical research
purposes or statistical purposes in accordance with Article $89(y)$ subject mplementation of the appropriate technical and organizational measures required by this Regulation in order to safeguard the rights and freedoms of the data subject" GDPR Art. 5.1(e)

Objective
Accountability is a new concept introduced in GDPR. The data controllers must be accountable and be able to demonstrate compliance with the provisions of the

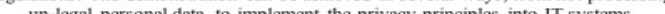

\section{Organizational Measures 뭄}

Strategy: By considering privacy in to the business and operational strategies, organizations can demonstrate strong commitment to GDPR

Policies, standards, awareness: adopting best practices, enforcing policies, and implementing processes can demonstrate strong commitment to GDPR. Considering Certified Products: one way to demonstrate compliance is to adopt products and
services that are build and certified with privacy in mind. EuroPriSe project is one
example

\section{Technical Measures :} Authentication \& Authorization: embedding necessary forms, dialogues,
notifications into information systems. Such as asking for consent before collecting notifications into information systion
location data of a mobile_app user

Tamper proof audit trails: Information systems should provide audit logs that can be used for monitoring compliance, and any future investigation or reporting. Tamper proof audits trails should be implemented strictly in IT Systems Monitoring: the goal with privacy should be always to prevent data leakage. Although montoring an be sech as a re-active approach, but it can help the Data Loss Prevention: preventing data from leakage on the way out from information protections. 